\title{
8
}

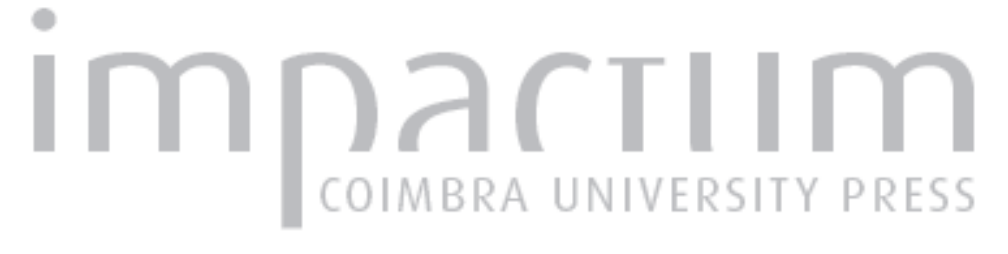

\section{[Recensão a] Fernando Catroga, A Geografia dos Afectos Pátrios, As reformas políticoadministrativas (Sécs. XIX-XX)}

\author{
Autor(es): $\quad$ Félix, Sofia
}

Publicado por: Centro de Informação Europe Direct de Aveiro; Centro de Estudos
Interdisciplinares do Século XX

URL

persistente:

URI:http://hdl.handle.net/10316.2/33994

DOI:

DOI:http://dx.doi.org/10.14195/1647-6336_11_23

Accessed : $\quad$ 26-Apr-2023 15:13:10

A navegação consulta e descarregamento dos títulos inseridos nas Bibliotecas Digitais UC Digitalis, UC Pombalina e UC Impactum, pressupõem a aceitação plena e sem reservas dos Termos e Condições de Uso destas Bibliotecas Digitais, disponíveis em https://digitalis.uc.pt/pt-pt/termos.

Conforme exposto nos referidos Termos e Condições de Uso, o descarregamento de títulos de acesso restrito requer uma licença válida de autorização devendo o utilizador aceder ao(s) documento(s) a partir de um endereço de IP da instituição detentora da supramencionada licença.

Ao utilizador é apenas permitido o descarregamento para uso pessoal, pelo que o emprego do(s) título(s) descarregado(s) para outro fim, designadamente comercial, carece de autorização do respetivo autor ou editor da obra.

Na medida em que todas as obras da UC Digitalis se encontram protegidas pelo Código do Direito de Autor e Direitos Conexos e demais legislação aplicável, toda a cópia, parcial ou total, deste documento, nos casos em que é legalmente admitida, deverá conter ou fazer-se acompanhar por este aviso.

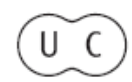


DEBATER

A EUROPA

jul-dez 2014

QUE EUROPA(S)?

CONTEXTOS E DESAFIOS 
Fernando Catroga, A Geografia dos Afectos Pátrios, As reformas políticoadministrativas (Sécs. XIX-XX), Edições Almedina, 2013, 406 p. ISBN 9789724050768

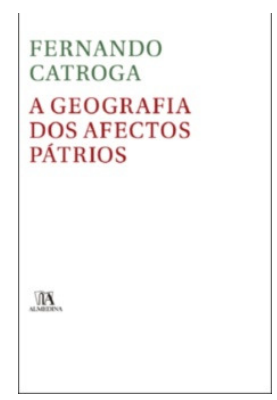

O microcosmos editorial enriqueceu-se em março de 2013 com a publicação sob a chancela do Grupo Almedina, da obra de um dos maiores pensadores eruditos da historiografia contemporânea em língua portuguesa, com linhas de estudo que compreendem desde a história das ideias, das mentalidades e representações intelectuais, a analítica da descristianização e secularização do discurso e das representações políticas $(1988 ; 1991 ; 1999 ; 2011)$ até ao estudo da história da história (1996), das relações memória/história (2000; 2003) a teoria da história (2009) e a história da cultura (1996).

Num movimento aglutinador de diversas publicações autónomas centradas na problemática do "Estado-nação" e através de um reordenamento lógico em analepse e prolepse que permite fazer avançar a ação ao longo do livro, o tema ganha expressão num discurso narrativo sistémico, no qual o autor investiga as mais relevantes ideologias e argumentos subjacentes ao debate da organização administrativa do País através dos diferentes regimes políticos (Monarquia Constitucional, República e Estado Novo), deambulando-se entre os vícios e as virtudes do centralismo e do descentralismo. Esta dicotomia entre centralismo (s) e descentralismo (s) marca as temáticas da governabilidade do território e da população (primeira parte), do provincialismo (segunda parte), do poder local como polícia (terceira parte) e o patriotismo das pequenas pátrias (quarta parte). $\mathrm{O}$ Estado enquanto entidade multiforme é caracterizado pelo autor, na senda da investigação diacrónica concetual de 
M. Foucault, por "estado polícia”, "estado cartógrafo", "estado higienista”, "estado pedagogo", "estado reitor" e "estado - nação império", evoluindo-se de uma aceção de police (de mera regulação) para uma de policy (de governabilidade).

Fernando Catroga deixa evidências na articulação do seu estudo, da profunda alteração imprimida pela assunção do indivíduo enquanto cidadão e átomo social. A relação com o poder (revestido sob a forma de corpo místico) deixou de ser mediada por estruturas corporativas passando a assegurar-se a integração do indivíduo na comunidade politicamente organizada a partir dos alvores do liberalismo em Portugal sob a forma de Estado, uno e indivisível.

Sob a égide da busca do "bem comum" e do princípio da unidade da soberania nacional fomentou-se a ubiquidade e a "presença panóptica da autoridade coativa e simbólica do Estado" (p. 11) e fez-se emergir uma massa de burocratas. As teorias organicistas, krausistas e positivistas serviram os intentos centralistas, contudo, a um Estado de cariz impessoal, o romantismo descentralista ("patrotismo de campanário") de Alexandre Herculano contrapôs os afetos das "pequenas pátrias", defendendo os municípios e as paróquias ou freguesias, pois, a "patrianaturae seria o húmus primordial que melhor afeiçoaria os sentimentos de pertença à patriacivitas" (p. 311).

O pensamento político descentralista fundiu duas ideias de pátria e consequentemente de nação: uma que remetia para um pendor mais étnico (nacionalidade) e outra de cunho jurídico-político (nação) (pp. 341, 344). Por outro lado, a controversa evolução no campo republicano do municipalismo republicano (J. F. Henriques Nogueira) para o unitarismo de modelo jacobino-napoleónico, segundo o paradigma de Bonnin, será relevante para compreender as próprias hesitações do modelo teórico do Estado e da sua constitucionalização que guiaram a subsequente implantação da República em 1910.

A "teorização contra-revolucionária" (p. 359) do Integralismo Lusitano, no decurso da I República e a tentativa de inoculação dos seus mitemas (reação, recristianização e retorno) debatida por P. Archer de Carvalho no movimento monárquico, corporativo, antiparlamentar, antiliberal e anticomunista, (Locus - Revista de História, Br. 2012, p.13 e segs.) servem também, para esclarecer que se o principal ideólogo do movimento, A. Sardinha "dizia respeitar a autonomia da freguesia, do município, da província, fazia-o porque via nestas sociedades intermédias, os órgãos da Monarquia corporativa que propugnava e cuja cabeça, mais mística do que física, pertencia ao Rei” (p. 362).

Ora, se o nacionalismo autoritário do Estado Novo propagandeou a ideia de "nação multicontinental e multiétnica, agora escudado, sobretudo em argumentos de 
cariz histórico e cultural", esta cruzar-se-ia com a matriz nacionalista e com a "patriacomunis de porte imperial" tanto quanto com a idealização das virtudes rústicas (pp. 390, 392, 374). No que concerne à organização administrativa do território assistiuse a uma divisão em províncias, distritos, concelhos e paróquias ou freguesias (com a progressiva secularização), destacando-se como protagonista o governador civil, enquanto presença microscópica do poder do Estado nas comunidades locais, estabelecendo-se uma "corrente vertical e descendente" (p. 234) e deste modo, de pendor centralista.

O provincialismo (11 "províncias-região") do Estado Novo credibilizado cientificamente pelo geógrafo Amorim Girão permitiu uma associação de concelhos com "afinidades geográficas, económicas e sociais" (p. 181), criando-se assim, uma "aliança entre regionalismo, patriotismo e nacionalismo" (p. 179), uma vez que, aportava "valências de compactação identitária e de robustecimento integrador à escala nacional", como explana Rui Cunha Martins no seu Método da Fronteira (2008, p. 169). Esta teorização falhou no entanto, no seu ideal de planificador regional.

A distritalização do País, saída da reforma administrativa da Revolução Liberal, não obstante, ser considerada uma divisão arbitrária de teor meramente estatístico (em função da área e da população) foi a mais perene, consolidando-se a sua existência em desfavor da província que carecia da tradição de uma prática política estruturada. Se os concelhos ou os municípios correspondem à célula ao qual pertence o indivíduo em primeiro plano devido a uma "génese espontânea e natural" (p. 215), na perspetiva descentralista de Herculano, a paróquia ou freguesia localiza-se no "centro nuclear da vida social, cívica e afetiva” (p. 215). A problemática centralismo/descentralismo como defende o autor, evidencia "assuntos que a atualidade política pôs na ordem do dia", pelo que, o conceito de Estado (tipo, forma, âmbito) é um debate que atravessou gerações e regimes políticos e permanece atual. Não obstante, uma leitura atenta permita dirimir argumentos relativos a posições que por vezes se antagonizam e que lançam luz sobre a atualidade: o escopo do estudo poderia deste modo revestir-se de uma maior amplitude, abrangendo com maior profusão os acontecimentos políticos do século XX, nomeadamente as opções políticas no pós Revolução de Abril, que foram pródigos em debates sobre a (s) função (ções) do Estado, que vão desde o conceito de "Estado mínimo", "Estado - providência" até ao debate da criação de Regiões Administrativas que culminou na realização de um referendo em plena Democracia. Mas por se tratar de um estudo historiográfico de grande envergadura, e não de uma 
peça incidental de um debate ou de uma agenda política imediata, ganha o maior peso esta publicação praticamente já esgotada nos escaparates.

Sofia Félix

Doutoranda CEIS20 